\title{
La narrativa existencial de Mario Vargas Llosa, réquiem por las víctimas en Perú
}

\section{The Existential Narrative of Mario Vargas Llosa, Requiem for the Victims in Perú}

\author{
Majlinda Abdiu ${ }^{1}$ \\ Universidad de Tirana (Albania)
}

Recibido: 03-09-19

Aprobado: 18-02-20

\section{Resumen}

El discurso literario se compromete bajo la perspectiva del siglo XXI a observar literariamente y justificar artísticamente la rebelión de Mario Vargas Llosa como escritor cosmopolita y opositor impecable de la violencia política $\mathrm{y}$ del terrorismo nacional e internacional contra cada represión, humillación y violación antihumana. El escenario ofrece reminiscencias claras en la filosofía marxista de la izquierda francesa, el espíritu existencialista de Sartre y Marcuse y el naturalismo sugestivo de Flaubert. El trabajo echa luz a la metamorfosis literaria de autoría bajo "el fuego" de la revolución, sinónimo de la deseada transformación democrática del país. La razón consiste en la antagónica realidad latina por donde prevalece la miseria política, económica, social y cultural. Las obras seleccionadas representan simbólicamente el inicio (La ciudad y los perros) y la finalización (Lituma en los Andes) del "boom", en el marco del movimiento sociocultural, literario y estético hispanoamericano de los años 60 del siglo pasado. Vargas Llosa será analizado como pionero del traslado estructural desde el énfasis mimético al poiesis estético de Platón, como producción de verdaderos valores artísticos. La investigación tratará la dualidad contradictoria, sin tapujos, de los sujetos artísticos que sincronizan simultáneamente el macrocosmos indígena poblado por la sierra inca y el macrocosmos burgués limeño. Este enfrentamiento cósmico de historias y culturas antagónicas irá a concretarse en la narrativa del

\footnotetext{
${ }^{1}$ (majlinda.abdiu@ hotmail.com) Doctora en literatura comparada, hispanista y lectora en la Universidad de Tirana, (Albania). Investigadora en el Proyecto de Investigación: "Proceso migratorio español hacia el Área Andina de Iberoamérica (Perú, Ecuador, Bolivia)”. Cátedra Santander-Presdeia. Investigador Principal-IP: Prof. Dr. José Manuel Azcona, Universidad Rey Juan Carlos de Madrid. Entre sus publicaciones cabe mencionar la siguiente: "América Latina en Albania. Los aspectos más evidentes" en el libro colectivo: Elementos identitarios de la imagen de España, América Latina y de su historia en Albania. Madrid: Editorial Dykinson, 2013, pp. 253-274.
} 
escritor a través del pasado simbólico y el realismo psicológico del presente. Esto, para formalizar la verdadera novela experimental peruana, y la vuelta al mundo próximo, mirado con ironía y humor.

Palabras-clave: violencia, narrativa existencial, pasado simbólico, realismo psicológico, Sendero Luminoso, Mario Vargas Llosa.

\begin{abstract}
The literary discourse commits itself under the perspective of the $21 \mathrm{st}$ century to literary observation and artistic justification of the rebellion of Mario Vargas Llosa as a cosmopolitan writer and impeccable opponent of political violence and national and international terrorism against every repression, humiliation and anti-human violation. This scenario offers clear reminiscences in the Marxist philosophy of the French left, the existentialist spirit of Sartre and Marcuse and the suggestive naturalism of Flaubert. The work sheds light on the literary metamorphosis of authorship under the "fire" of the revolution, synonymous with the desired democratic transformation of the country. The reason is the antagonistic Latin reality where political, economic, social and cultural misery prevails. he selected works symbolically represent the beginning (The city and the dogs) and the end ("Lituma in the Andes") of the "boom", within the framework of the Latin American sociocultural, literary and aesthetic movement of the 1960s. Vargas Llosa will be analyzed as a pioneer of the structural transfer from Plato's mimetic approach to aesthetic poiesis, as the production of true artistic values. The research will deal with the contradictory duality, without hesitation, of the artistic subjects that simultaneously synchronize the indigenous macrocosm populated by the Inca mountains and the Lima bourgeois macrocosm. This cosmic confrontation of antagonistic stories and cultures will become a reality in the writer's narrative through the symbolic past and the psychological realism of the present. This, to formalize the true Peruvian experimental novel, and the return to the next world, viewed with irony and humor.
\end{abstract}

Key-words: Violence, Existential Narrative, Symbolic Past, Psychological Realism, Shining Path, Mario Vargas Llosa.

\title{
1. Introducción
}

El nombre de Mario Vargas Llosa se conoce merecidamente como ilustre artista de letras. Intelectual poliédrico, escritor cosmopolita y opositor impecable de la violencia política y del terrorismo nacional o internacional, 
desde joven fue impregnado con las ideas marxistas de la izquierda francesa, el espíritu existencialista de Sartre y Marcuse y el naturalismo sugestivo de Flaubert, como pionero del traslado estructural desde el énfasis mimético al poiesis $^{2}$ estético. Dicha influencia sociocultural resultó muy poderosa en la narrativa de Vargas Llosa, convirtiéndose en el símbolo del realismo peruano y del "boom" hispánico de los años $60^{3}$. Ello, por el metalenguaje transgresivo y los temas novedosos en los que convivían lo explicable y lo inexplicable, lo corriente, y lo insólito. Algunos de los literatos que cultivan y promueven su interculturalidad mundial son Juan Rulfo, Miguel Ángel Asturias, Jorge Luis Borges, Julio Cortázar, Gabriel García Márquez, Isabel Allende, Arturo Uslar Pietri o Carlos Fuentes. Los sujetos artísticos tratan sin tapujos la dualidad contradictoria entre el macrocosmos indígena poblado por la sierra inca y el macrocosmos burgués limeño. Este enfrentamiento cósmico de historias y culturas antagónicas se termina por concretar, sin embargo, en la narrativa de Vargas Llosa a través del pasado simbólico y del realismo psicológico del presente. Ello, formalizando una nueva novela experimental, y la vuelta a un mundo próximo, mirado con ironía y humor. Muy temprano se conocerá la vocación literaria del escritor justificándola como

la convivencia potencial de su vida personal con otra vida paralela, por donde se refugiaba contra la adversidad, que volvía natural lo extraordinario y extraordinario lo natural, disipando el caos, embelleciendo lo feo, eternizando el instante y tornando la muerte un espectáculo pasajero ${ }^{4}$.

Se partirá investigando la metamorfosis literaria de Vargas Llosa bajo "el fuego" de la revolución, sinónimo de la deseada transformación democrática del país. La razón consistía en la antagónica realidad latinoamericana por donde prevalecía la injusticia política, la ignorancia masiva y la desigualdad genérica. Por ello, el artista se incorpora como intelectual comprometido y manifiesta explícitamente su apología por la Revolución cubana, calificada como "un festín de razones para ser insumiso y vivir"s. Vargas Llosa sería fiel a sus actitudes civiles y a su autenticidad literaria llena de "sus demonios artísticos".

El discurso literario se compromete a echar más luz en La ciudad y los perros y Lituma en los Andes, que respectivamente simbolizan el inicio y la finalización del "boom" del autor. Aunque escritas con diferencia de tres décadas entre ellas, las novelas marcan connotaciones temerosas de la

\footnotetext{
${ }^{2}$ El término Poesis significa producción de valores artísticos, según la filosofía de Platón.

3 Enrique Ortiz Aguirre, “¿El realismo mágico hispanoamericano constituye un movimiento estético?", en La literatura hispanoamericana en 100 preguntas, Madrid, Nowtilus, 2017, pp. 325326.

${ }^{4}$ Vargas Llosa: La literatura es fuego. Según la pág. web: www.literaterra.com/mario_vargas Vargas Llosa/la_literatura_es_fuego/.CConsultada el día 12 de mayo de 2019.

${ }^{5}$ La literatura es fuego..., ídem.
} 
violencia física, psicológica, política y social, manifestadas en el escenario artístico peruano de cada macrocosmos literario. El primer caso se refiere a la inmensa violencia instalada y a sus recurrencias trágicas convividas en la academia militar Leoncio Prado de Lima. Una institución totalmente arbitraria, mera jungla escolástica en donde "¡te comen si no comes!”. El segundo caso analítico se refiere a la historia trágica de Andamarca, un campamento minero ubicado en el seno de la cordillera andina, en donde los serranos enfrentan el peligro demoníaco del pasado y el terror ilimitado del presente representado por Sendero Luminoso. Simultáneamente se analizará el andamiaje del microcosmos humano que transcurre en los senderos psicológicos desde la línea transgresiva de las víctimas a la filosofía existencial de los sobrevivientes, como testigos de la posición pacifica del autor en cada situación.

\section{El fuego de la Literatura}

Mario Vargas Vargas Llosa tenía solo 31 años cuando apareció en Caracas y ofreció uno de sus discursos más históricos, el día 4 de agosto de 1967, con el título La literatura es fuego. La razón consistía en recibir el Premio de la Crítica y el Premio Internacional de Literatura Rómulo Gallegos de novela de aquel año ${ }^{6}$. Era el momento para articular sus ideas transformadoras que proclamaban el fuego, la transformación, la página nueva, el impulso decisivo, la salida dura, la verdadera inspiración por donde debería recurrir la literatura. El mensaje discursivo se concentraba en su vocación literaria que le había acompañado eternamente a pesar de autodenominarse "brujo de palabra", "arquitecto osado de imágenes" o "explorador fulgurante de sueños". Mario Vargas Llosa representa la vitalidad arrolladora, escenas de una deliciosa felicidad erótica y una implacable denuncia de la corrupción política y periodística. El escritor peruano constituye uno de los artistas indiscutibles de la literatura cosmopolita universal, con una obra abrumadora y auténtica, por la que aparece el existencialismo vital y la lírica sentimental, las luces y las sombras del verdadero artista.

La historia política de Vargas Llosa es indisociable de su recorrido literario, dada su inclinación e incorporación intelectual, muy de moda en los años 60 del siglo XX. Sus inicios políticos se relacionan con el existencialismo cultural de Sartre y Marcuse como representantes ideológicos de la izquierda francesa y la simpatía por la Revolución cubana. Dicho contexto promocionaba una nueva estrategia global, cultural o sociopolítica, como ocurrió en la España de los años 60. Allí apareció la discusión estético-ideológica considerada "realismo social"

\footnotetext{
${ }^{6}$ Se trata de la novela La Casa verde, cuyo núcleo temático se relaciona con la ciudad de Piura, al borde del desierto, y una zona de la Amazonia poblada de caucheros.
}

Araucaria. Revista Iberoamericana de Filosofia, Política, Humanidades y Relaciones Internacionales, año $22, \mathrm{n}^{\circ} 43$. Primer semestre de 2020. Pp. 467-490. ISSN 1575-6823 e-ISSN 2340-2199 https://dx.doi.org/10.12795/araucaria.2020.i43.23 
y "reflexión colectiva" por revocar la contribución de Machado, Unamuno, Valle-Inclán o Baroja, y también por apoyar la actividad editorial de empresas como Taurus en Madrid y Seix Barral en Barcelona.

Otro rasgo importante fue el conocimiento de la obra literaria de los exiliados de 1939, la recepción entusiasta del "boom" de la literatura hispanoamericana y el vigoroso rebrotar de las culturas nacionales en Cataluña, Galicia y País Vasco ${ }^{7}$. En otros países europeos el movimiento se extendió en el campo literario, antropológico, histórico, social, musical y psicológico. La razón consistía en el apoyo de la filosofía marxista-leninista por los intelectuales que inspiraban la transformación revolucionaria del régimen político como el único camino hacia la verdadera democracia y la independencia nacional. Esta demanda histórica planteó el protagonismo "del hombre nuevo", convirtiendo al intelectual comprometido en el "líder popular" como fue el caso político de Vargas Llosa.

Volviendo a su discurso Literatura es fuego, se puede evidenciar que el escritor plantea la tesis del cambio revolucionario, porque "en el dominio de la literatura, la violencia es una prueba de amor" . Vargas Llosa prima la creación de la cultura política transformadora como un paso fundamental y decisivo que abre el camino de la transformación socioeconómica y cultural del país. En este contexto, él instaba a muchos escritores la condición histórica de carácter operacional: "habría que recordar que muchos de los escritores de la época estaban convencidos de que no había posibilidad de cambio social si no se operaba violentamente contra las injustas estructuras de dominación social"9. El Nobel peruano asume así la vinculación entre literatura y violencia, no solo en su obra novelística, sino en sus propias reflexiones sobre la naturaleza de la literatura. Según Jorge Valenzuela Garcés, el artista articula el rol de literatos disponibles para encender el fuego de revoluciones y de las transformaciones verdaderas en su país:

El fuego de la literatura es, pues, una metáfora que ilustra la regeneración que el fuego lleva a cabo cuando destruye algo contaminado y permite el yacimiento de lo incontaminado, de lo puro. Es ese fuego que se viabiliza a través de ironías, de sátiras, que irán de lo adjetivo a lo esencial, de lo pasajero a lo

\footnotetext{
${ }^{7}$ Según Mainer, "una buena parte del protagonismo intelectual español había pasado a una promoción más joven, "Los hijos de la guerra", cuya rebeldía moral era su fe de vida, y para quienes la contienda se convirtió en un misterio de dolor, en la escena primitiva que mostraba a la par su inocencia y culpabilidad de sobrevenidos testigos. Dentro de la narrativa española de la época, se encuentra Los bravos de Jesús Fernández Santos, El fulgor y la sangre de Ignacio Aldecoa, Duelo en el paraíso de Juan Goytisolo, El Jarama de Rafael Sánchez Ferlosio, Ritmo lento de Carmen Martín Gaite, Los hijos muertos y la primera memoria de Ana María Matute y Tormenta de verano de Juan García Hortelano. José Carlos-Mainer, "Síntomas del malestar", en Historia mínima de la literatura española. Del "Cantar de Mio Cid al siglo XXI", Madrid, Turner, 2014, pp. 193-194.

${ }^{8}$ La literatura es fuego..., idem.

${ }^{9}$ La literatura es fuego..., idem.
} 
permanente, del vértice de la base a la pirámide social y que serán proferidas por el escritor en cualquier circunstancia y sin mediar autorización o diálogo posible. Finalmente, el fuego de la literatura es configurado como el ardor con que se excitan las pasiones humanas, tanto las positivas, pensemos en el amor, como las negativas como el odio que, el marco que propone el discurso se constituye en sentimientos o emociones sin los cuales el escritor estaría imposibilitado de representar eficientemente la realidad ${ }^{10}$.

A pesar de la complicidad histórica del continente en los años 60, todo coincidió con la culminación de la explosión literaria y la inclinación existencialista del nuestro escritor. Disfruta del contexto para expresar su apología por la Revolución cubana como la única solución transformadora y efectiva hacia el cambio radical político, entendida como "un festín de razones para ser insumiso y vivir descontento".

Durante los años 1968-1975, el escritor simpatizó con las reformas emprendidas por el gobierno militar del presidente peruano Juan Francisco Velasco Alvarado (1968-1975) sin tolerar la censura política hacia la clase media peruana. Al ser elegido presidente de la Organización Mundial de los Escritores (1976), denunció los actos violentos contra los intelectuales argentinos bajo el régimen militar de Rafael Videla. Vargas Llosa presidió la Comisión Investigadora sobre el Caso Uchuraccay (1983) durante los años negros en Perú, comprobando el terror generado por Sendero Luminoso. El escritor consiguió presidir también el Consejo del gobierno en Perú (1984) bajo el gobierno de Fernando Terry. Cuatro años más tarde se designa comprometido políticamente en defensa del interés público y dirige su partido político "FREDEMO", el cual le permitió postularse en las elecciones presidenciales del año 1990 en Perú.

Bajo amenazas y presiones políticas se traslada a Madrid, obteniendo la ciudadanía española en 1993 y sin renunciar a defender los derechos humanos en México, amenazados por el gobierno de Carlos Salinas (1994). Más tarde se erige presidente de la Comisión Estatal para encabezar el proceso del conflicto armado en Perú. Sus primeros trabajos literarios hablan de un intelectual ilustre y visionario por implementar y respetar dos objetivos fundamentales en su arte: animar la agitación pública y proclamar su anticonformismo contra la injusticia y la arbitrariedad como enemigos mortales del progreso humano. Vargas Llosa sustenta la verdad, aunque su camino es tortuoso y abrupto:

Como ayer, como ahora, si amamos nuestra vocación, tendremos que seguir librando las treinta y dos guerras del coronel Aureliano Buendía, aunque, como a él, nos derroten en todas... Un agitador decidido y estimulador de cambios y

${ }^{10}$ Jorge Valenzuela Garcés, «El héroe intelectual. La figura del poeta mártir...», en Mario Vargas Vargas Llosa. Según web: www.vallejoandcompany.com/la-figura-del-poeta-martir-en-la-liter..., consultada el día 15 de mayo de 2019. 
mejoras. La novela es un acto de rebelión contra la realidad, obra del Dios. En el mundo de la ficción, la verdad se llama autenticidad y es subjetiva. El escritor debe ser ante todo autentico y fiel a sí mismo, fiel a sus propias obsesiones, a sus fantasmas, a sus demonios, a su locura, a su mugre ${ }^{11}$.

Se habla de una productividad literaria inmensa que lleva la firma del artista según sus respectivos volúmenes: Contra viento y marea (1983, 1986,1990) y La verdad de las mentiras (1990), además de los profundos estudios monográficos dedicados a escritores como Joanot Martorell en Carta de batalla (1969), Gabriel García Márquez en García Márquez: Historia de un deicidio (1971), Gustave Flaubert en La orgía perpetua (1975), Jean Paul Sartre y Albert Camus (1981), José María Arguedas en Utopía arcaica (1996). Vargas Llosa es el artista peruano que mejor explica la génesis de novelas como ocurre en Historia secreta de una novela (1971). La vertiente política es igualmente conocida y se expresa en una serie de artículos recopilados como Desafíos a la libertad (1994), El lenguaje de la pasión (2000) o las memorias El pez en el agua (1993), en donde se narra la experiencia política en las elecciones presidenciales de Perú.

$\mathrm{Su}$ inspiración artística parece cultivada gracias a los modelos internacionales que adoraba y a los protagonistas de valores universales, quienes influyeron directamente en su éxito. Es el caso de mencionar la novela caballeresca de Martorell y la narrativa mágica de Gabriel García Márquez. Vargas Llosa prefiere e imita el mundo irreal poblado de sueños, mitos, leyendas, fantasía. Flaubert, gracias a su naturalismo francés, le inspira en tratar literariamente la mediocridad humana, el adulterio, la hipocresía, la violencia y el sexo. No queda atrás la influencia de Faulkner en las páginas de Vargas Llosa, cumpliendo con las múltiples perspectivas de los norteamericanos, los saltos temporales, la desaparición del narrador detrás del coro narrativo y la presencia multilateral de la comunidad anónima de protagonistas.

El artista peruano nunca se puso de acuerdo con la generación literaria del 50, a pesar de compartir con sus compatriotas cierta oposición contra la corrupción sociopolítica nacional. Su espacio artístico llega a superar las fronteras físicas de su tierra para ubicarse artísticamente también en Brasil (La guerra del fin del mundo), en la República Dominicana (La fiesta del Chivo), incluso hasta en Francia y Tahití (El paraíso en la otra esquina). Sus primeros pasos literarios estaban dominados por el intento de vencer el fracaso o las dudas existenciales propias, reflejos fieles de su experiencia personal en Cochabamba de Bolivia y Piura de Lima.

El espacio creativo de Vargas Llosa incluye la extensa imaginación y la predisposición incondicional si nos referimos a sus numerosas novelas, dramas,

\footnotetext{
${ }^{11}$ La literatura es fuego..., idem.
} 
memorias, antologías, ensayos para incorporarse con mucha dignidad a la mejor narrativa peruana de los años 60 . En esta época, la novela peruana ofreció al mercado cultural (nacional e internacional) interesantes narradores, quienes ocuparon literariamente dos mundos distintos. Por un lado, lo indígena, poblado de imágenes de la sierra y en frente se ponía el mundo limeño, símbolo de la burguesía. El enfrentamiento cósmico de dos historias y culturas antagónicas se realiza por aplicar la evocación simbólica y el realismo psicológico del mundo, mirado con ironía y humor. Unos de los mejores narradores peruanos además de Vargas Llosa eran José María Arguedas, conocido por su extensa novela Todas las sangres (1964), y Julio Ramón Ribeyro, quien denunció artísticamente el fracaso humano en el campo social y psicológico en sus novelas Los gallinazos sin pluma, Cuentos de circunstancias o La juventud en la otra ribera. Según José Miguel Oviedo, el "boom" literario pone de manifiesto a Mario Vargas Llosa como el peruano más joven, gracias a su abrumadora y cualitativa producción novelística:

Atrae su pasión creadora, su temprana madurez intelectual acompañante de la estética sirvieron para que el Boom tuviese en él el protagonista, un portavoz y un interlocutor de excepcional aptitud para cumplir esos papeles con una tenacidad y diligencia a toda prueba ${ }^{12}$.

Las páginas literarias confirman la pasión, la rigurosidad y la disciplina creativa, la cohesión y la amplitud visionaria, la dignidad genérica, la presencia incondicional desde lo nacional a lo continental, en obras como Conversación en la catedral (1969), Pantaleón y las visitadoras (1973), La tía Julia y el escribidor (1977), La guerra del fin del mundo (1981), Historia de Mayta (1984), ¿Quién mató a Palomino Molero? (1986), El hablador (1987), Elogio de la madrastra (1989). No quedan atrás otros escritos dramáticos como La señorita de Tacna, La Chunga y El loco de los balcones, igual que estudios literarios ensayísticos, como García Márquez: historia de un deicidio (1971), La orgía perpetua: Flaubert y Madame Bovary (1975) y El pez en el agua (1993). Con la majestuosa novela Lituma en los Andes consigue obtener el Premio Planeta en 1993, y continúa escribiendo obras como Los cuadernos de Don Rigoberto, La fiesta del Chivo, El paraíso en la otra esquina, Travesuras de la niña mala, El sueño de la celta, El héroe discreto y Cinco esquinas. En 1986 comparte con el artista Rafael Lapesa el Premio Príncipe de Asturias de las Letras, en 1994 el Premio Miguel de Cervantes de Literatura y en 2010 el Premio Nobel de Literatura.

Otro mérito de Vargas Llosa fue su inmenso trabajo para difundir la cultura del libro en Perú, proclamándolo "un instrumento activo, y auténtico".

12 José Miguel Oviedo, Historia de la Literatura Hispanoamericana, 4, de Borges al Presente. "El boom: el centro, la órbita y la periferia”, Madrid, Alianza, 2012, p. 316.

Araucaria. Revista Iberoamericana de Filosofia, Politica, Humanidades y Relaciones Internacionales, año $22, \mathrm{n}^{\circ} 43$. Primer semestre de 2020. Pp. 467-490. ISSN 1575-6823 e-ISSN 2340-2199 https://dx.doi.org/10.12795/araucaria.2020.i43.23 
La misma opinión comparte Julio Cortázar que acentúa el rol indispensable del libro, constituyendo un santuario de ciertos órdenes de ideas y sentimientos, porque el libro es

El paradigma de la dureza de la estatua - allí donde la gracia queda presa para siempre, el libro responde por analogía a la concepción que tan lujosamente explayara Víctor Hugo en Notre-Dame de Paris: sucesor de la arquitectura; columnas mentales, arquitrabes del sentimiento, fustes del espíritu; libro para durar ${ }^{13}$.

La narrativa de Vargas Llosa ofrece una apariencia despreocupada hacia las formas exteriores de su creación literaria, sea personal o general. Todo eso ocurre porque la verdadera batalla del libro se libra allí, donde dos actitudes ante la realidad y el hombre se descubren antagónicas. Pues se trata de un artista realista que editó, según Cortázar:

Un libro atando páginas sueltas a un arbusto de alambre, su violento desafío lleno de burla, mal gusto, fastidio, encumbre una denuncia de otro orden, el estadio intermedio entre una etapa de destrucción sobre bases esencialmente distintas ${ }^{14}$.

$\mathrm{Su}$ estilo se caracteriza por la "destrucción lingüística", "la agresión literaria", "el abandono del tradicional", "la despedida de las tradicionales convicciones". Destaca la capacidad creativa en su línea estructural de relatar, por utilizar la técnica contrapuntística y combinar escenas alternativas para reflejar artísticamente los conflictos de cada época y las tensiones injustificadas que transcurren a la raza humana. En la narrativa de Vargas Llosa se reconstruye la peripecia vital de cada uno de sus personajes artísticos, quienes recurren al conocido flashback, saltando de un plano temporal al otro, de forma que el lector ha de ubicar escenas en la secuencia cronológica adecuada.

El artista parece muy apasionado por sus apuntes biográficos, convertidos literariamente en reflexiones psicológicas de los respectivos sujetos. Se pueden considerar un suplemento para identificar a los protagonistas paso tras paso. No podría faltar la presencia del monólogo interior, con el desorden y la transgresión sintáctica que le son propios, combinado con la voz narradora en tercera persona y los recuerdos en primera. Refiriéndose a su literatura, aparentemente los tonos estéticos respectivos se convierten en insólitos y rebeldes. El túnel verbal del artista se compromete desde el primer momento a ofrecernos un texto distinto, impactante, escandaloso, temeroso, extraordinario que superará la misma ficción, hiperbólico y casi perverso.

\footnotetext{
${ }^{13}$ Julio Cortázar, «El conformista y el rebelde», en Obras Críticas, Barcelona, Galaxia Gutenberg, 2006, p. 58.

14 "El conformista y el rebelde...", p. 59.
} 
La narrativa artística confirma el verdadero modo verbal de ser hombre, su avance en el profundo y oscuro túnel, quien en plan extraverbal se vuelve contra lo verbal desde el verbo mismo para denunciar, según Cortázar, a la literatura como condicionante de la realidad. Por eso, la literatura y, sobre todo, el caso de la novela de Vargas Llosa, es una forma de manifestación verbal que sirve para examinar el método, el mecanismo del terror y violencia por el cual se articula un ejercicio verbal a cierta revisión de la realidad. Mario Vargas Llosa mantiene estrechos vínculos con el Realismo, si bien en cada una de sus novelas experimente estructuras nuevas y novedosas formas de expresión.

En su carrera de novelista la nota constante es lo imprevisible, la novedad. No hay un solo libro que se parezca al anterior y la capacidad del escritor para renovarse es especialmente prodigiosa. El investigador Giuseppe Bellini sustenta que:

\begin{abstract}
Vargas Llosa representa a veces una lectura rescatada por lo atractivo del juego verbal, por el desarrollo de una trama violenta y patética al mismo tiempo, que vuelve una y otra vez a la condición de la infancia. Vargas Llosa siempre ha afirmado que escribir novelas es un acto de rebelión contra la realidad, obra del Dios, y, por consiguiente, un "deicidio", pero sus obras acaban siempre por acusar al hombre, verdadero artífice de esa realidad ${ }^{15}$.
\end{abstract}

Así, Mario Vargas Llosa está convencido de que su existencia creadora es la de un intelectual creador, cuya obra podría ser el fruto de una larga confrontación lingüística, que es su realidad profunda, la realidad verbal que su don narrador utiliza para aprender la realidad total en todos sus múltiples contextos.

\title{
3. El fraude de la "Academia" Militar
}

Vargas Llosa pasa dos años de su adolescencia en la Academia Militar Leoncio Prado (1950-1951) y, tiempo después, construye el artificio literario, el sujeto artístico evocando en retrospectiva los acontecimientos temerosos ocurridos en aquella institución, conllevando en sus espaldas la figura del autor "inconforme, que sostiene postulados éticos"16. Así, la experiencia personal se convierte en una historia impersonal narrada en La ciudad y los perros. En cada página se enfrenta el misterio escondido o aparecido entre las imágenes reales y los detalles psicológicos. Los dos años transcurridos en la academia

${ }^{15}$ Giuseppe Bellini, "La narrativa del siglo XX: La nueva novela y su auge. Mario Vargas Llosa", en Nueva historia de la literatura hispanoamericana, Tercera Edición, Madrid, Castalia, 1997, pp.514-515.

16 “Mario Vargas Llosa: los secretos de un novelista”, en El Espectador, Cultura, 27 de noviembre 2014. Consultado el día 10 de mayo 2019.

Araucaria. Revista Iberoamericana de Filosofia, Política, Humanidades y Relaciones Internacionales, año $22, \mathrm{n}^{\circ} 43$. Primer semestre de 2020. Pp. 467-490. ISSN 1575-6823 e-ISSN 2340-2199 https://dx.doi.org/10.12795/araucaria.2020.i43.23 
se memorizan por el fraude institucional, la injusta arbitrariedad militar y la especulativa educación escolástica.

Los cadetes del tercer año pierden su identidad bajo las nuevas condiciones del círculo violento, deshumano y armado. Se trata de una banda de jóvenes que dirigen y dominan a cualquier débil gracias a la ley de jungla porque “đdebes comer, si no te comen!”. Allí predomina el instinto existencial que afecta incondicionalmente al ser humano de caer, hundirse, sobrevivir, resistir, sublevarse o traicionar y morir dentro de la jungla limeña. Los cadetes se convierten en animales metafóricos guardando y defendiendo duro sus territorios o intereses entre la vida y la muerte. La novela está inspirada por la filosofía existencial de Malraux, Kafka, Unamuno y Sartre, personajes adorados por Vargas Llosa. La misma actitud filosófica comparte Julio Cortázar, quien acentúa el rechazo del tradicionalismo y sus auxiliares en nombre del existencialismo:

Propongo el término existencialismo libre de toda implicación tópica. Aludo a un estado de conciencia y sentimiento del hombre de nuestro tiempo, antes que a la sistematización filosófica de una concepción o método. En la línea de creación verbal del siglo, la actitud profana, libre de consignas y manifestándose en fecundos antagonismos espirituales -como cabe columbrar si enumeramos uno tras otro a Malraux, Kafka, Unamuno y Sartre ha tenido por dominador común el cuidado, la preocupación angustiosa emanante de un valeroso e implacable cateo de la condición humana. El intuir existencialista de la soledad resulta producto más o menos aceptado o entendido de esta inmersión del hombre mismo: rechazo de sostenes tradicionales, teologías auxiliares y esperanzas teológicas. La soledad, vivencia de esos "solo que no son únicos de estar solos" se ha mostrado como una soledad de Dios, hasta el ateísmo expreso de la forma dialéctica por Sartre ${ }^{17}$.

Vargas Llosa rechaza radicalmente el romanticismo mágico, individualista, ahistórico, irreal, que nunca lo mantuvo, y asume conscientemente la influencia sartriana como percepción filosófica y creación artística, definiendo el origen de cada cambio porque Sartre con su filosofía existencial le había convencido de que:

Con la vocación literaria uno no actuaba de manera despectiva sobre los problemas de la sociedad, sino que los cambios en sus orígenes eran siempre ideas. Porque hacer literatura es una forma de participar en los cambios histórica en una manera muy efectiva ${ }^{18}$.

17 Julio Cortázar, "Existencialismo", en Obra Crítica, Obras Completas VI, ED., Barcelona, Galaxia Gutenberg, 2006, pp. 110-111.

${ }^{18}$ Mario Vargas Llosa: El escritor y sus demonios. Según la pág. web: www.chicagotribune.com/.../ ct-hoy-8834484-mario-vargas-1 Consultada el día 13 de mayo 2019.

Araucaria. Revista Iberoamericana de Filosofia, Política, Humanidades y Relaciones Internacionales, año $22, \mathrm{n}^{\circ} 43$. Primer semestre de 2020. Pp. 467-490. ISSN 1575-6823 e-ISSN 2340-2199 https://dx.doi.org/10.12795/araucaria.2020.i43.23 
En la novela La ciudad y los perros, los débiles padecen del victimismo incurable sin excluir la muerte. Vargas Llosa maduró en esta dura atmosfera cumpliendo la voluntad de su padre. El escritor lo recuerda como una persona contraria a la literatura, pensando que la rigurosidad de un colegio militar sería la mejor cura para la vocación extravagante de su hijo ${ }^{19}$. La narrativa habla del enfrentamiento y de la resistencia, a pesar de que la muerte persigue a todos. Allí a todos les cuesta convivir y sobrevivir, aunque en condiciones físicas extremas como es el caso del cadete Cava:

...Sintió frío. Los baños estaban al fondo de las cuadras, separados de ellas por una delgada puerta de madera, y no tenían ventanas. En años anteriores, el invierno sólo llegaba al dormitorio de los cadetes, colándose por los vidrios rotos y las rendijas; pero este año era agresivo y casi ningún rincón del colegio se libraba del viento, que, en las noches, conseguía penetrar hasta en los baños, disipar la hediondez acumulada durante el día y destruir su atmósfera tibia. Pero Cava había nacido y vivido en la sierra, estaba acostumbrado al invierno: era el miedo lo que erizaba su piel ${ }^{20}$.

Enfrentando artísticamente el pasado simbólico con el presente psicológico, Vargas Llosa no para de estigmatizar, ironizar y denunciar el esquema y los mecanismos que generan violencia en la academia militar. Los mensajes se dirigen al racismo humano, al machismo injustificado y a la injusticia desflemada presente en la sociedad peruana de la época. El mérito de autoría consiste en la aportación de una visión extensa y temerosa de la violencia física, psicológica, genérica o sociocultural. Podemos referirnos al personaje de Esclavo que parece tan trágico y aterrorizado bajando las escaleras del comedor mandado por sus compañeros, ya convertidos en criaturas fieras de la jungla. Predomina el estilo realista y la fluidez de los detalles miméticos de la época que ayudan al lector percibir psicológicamente la siguiente escena antihumana:

El esclavo estaba solo y bajaba las escaleras del comedor hacia el descampado, cuando dos tenazas cogieron sus brazos y una voz murmuró a su oído: “¡venga con nosotros, perro!” Él sonrió y los siguió dócilmente. A su alrededor, muchos de los compañeros que había conocido esa mañana eran abordados y acarreados también por el campo de hierba hacia las cuadras de cuarto año. Ese día no hubo clases. Los perros estuvieron en manos de los de cuarto desde el almuerzo hasta la comida, unas ocho horas. El Esclavo no recuerda a qué sección fue llevado ni por quién. Pero la cuadra estaba llena de humo y de uniformes y se oían risas y $\operatorname{gritos}^{21}$.

${ }^{19}$ El escritor y sus demonios..., idem.

${ }^{20}$ Mario Vargas Llosa, La ciudad y los perros, Madrid, Alfaguara, 1997, p. 21.

${ }^{21}$ La ciudad y los perros, p. 20. 
La novela de Vargas Llosa manifiesta así la dualidad imaginativa paragógica, constituida por la imagen extrínseca (la educación militar dentro del contexto urbano) y la imagen intrínseca (la imagen urbana dentro del contexto educativo de los años 50). El espectro artístico lleva el peso dramático dentro del espacio atemporal bajo los ritos machistas, la sexualidad frenética y los tabús como una implícita protesta a los códigos militares de Perú. Se trata literariamente de una sociedad estrictamente jerarquizada donde los diabólicos adolescentes crean sus propias jerarquías de "jefes", "perros", "esclavos" como una reproducción perversa de la jerarquía oficial. Según Oviedo, se trata de una muerte que puede ser accidental o criminal, conduce una violación del pacto del silencio que rige el círculo clandestino y su crisis acarrea la de la institución y alcanza luego a todos los estamentos sociales, desde el núcleo familiar hasta el ejército:

Un motivo central en el relato es la impostura, la urgencia por representar un papel para no ser víctima de la sorda violencia enquistada en las instituciones; existe una agresividad contra todo lo establecido, cuyas raíces podridas se hacen visibles sobre todo en los pasajes que narran el pasado de los adolescentes previo a su llegada al colegio. Hay un débil estudio de conductas y reacciones ante las presiones del medio que determinan quienes mandan y quienes obedecen ${ }^{22}$.

Por todo ello Vargas Llosa se incorpora con dignidad al lado de los importantes literatos nacionales de la época para proclamarse contra el canibalismo militar. Ahí, el ser sobrevive entre vida y muerte. Otro camino intermedio parecía irreal. Ser superior/inferior, ser blanco o negro, ser rico o pobre, ser padre o hijo. Todo se repite y se vuelve a vivir dentro del tiempo y espacio artístico. Todo lo que convive el Esclavo es un infierno sin nombre, ni límites. El grotesco llega al nivel del burlesco todopoderoso:

Para empezar, cante cien veces "soy un perro", con ritmo de corrido mexicano. No pudo. Estaba maravillado y tenía los ojos fuera de las órbitas. Le ardía la garganta. El pie presionó ligeramente su estómago. - No quiere - dijo la voz - El perro no quiere cantar. $\mathrm{Y}$ entonces los rostros abrieron las bocas y escupieron sobre él, no una, sino muchas veces, hasta que tuvo que cerrar los ojos. Al cesar la andanada, la misma voz anónima que giraba como un torno, repitió: - Cante cien veces "soy un perro", con ritmo de corrido mexicano ${ }^{23}$.

Las peleas reflexionan el antagonismo institucional, urbano, social, cultural, y más. Los cadetes de la academia se llaman "perros", y deben sentirse y comportarse así. Bajo la dirección del Jaguar (seudónimo del personaje

\footnotetext{
${ }^{22}$ José Miguel Oviedo, "Vargas Llosa: Jerarquías de la realidad y el poder", en Historia de la Literatura Hispanoamericana. De Borges al Presente, Madrid, Alianza, 2012, pp. 316-317.

${ }^{23}$ La ciudad y los perros..., p. 20.
} 
diabólico y violento), roban las preguntas de un examen de química. El Esclavo (cobarde, sumiso y oportunista), siempre al margen del grupo, denuncia al ladrón para que sea permitido salir el fin de semana e irónicamente se encuentra asesinado entre basuras. La angustia mortal acompaña a todos, generando a continuación el enfrentamiento entre el Jaguar y el Poeta, Alberto, quien denuncia al protagonista por su crimen, robo y asesinato. Luego, el recorrido del texto y subtexto artístico va en progresión: el robo, el crimen y por encima de todo la inseguridad del presente. La estructura sincrónica de la academia queda en la subconsciencia de Vargas Llosa bastante deformadora desvelando los peores instintos humanos para reconocer la autodestrucción humana. El estilo narrativo los convierte en verdugos artísticos dominados por el mal, lo grotesco y burlesco. El fragmento ilustrado confirma la previa muerte. Nos impresiona el estilo directo, rígido, macabro:

Apenas cruzó la puerta, la sonrisa en los labios aún, se sintió golpeado en la espalda. Cayó al suelo, giró sobre sí mismo, quedó tendido boca arriba. Trató de levantarse, pero no pudo: un pie se había instalado sobre su estómago. Diez rostros indiferentes lo contemplaban como a un insecto; le impedían ver el techo ${ }^{24}$.

Allí conviven el Jaguar, la víctima, el Esclavo, los payasos infringiendo las reglas (escritas o no) para que puedan existir. Se enfrenta la historia interior con la exterior, el individuo con el grupo, el día con la noche por donde el orden arbitrario sustituye al orden lógico, natural. La academia se percibe, pues, como un fraude horroroso que deprime y asola a su público juvenil desde el primer momento. El poeta describe así el ámbito castrense: "Aquí eres un militar, aunque no quieras. Y lo que importa en el Ejército es ser un buen macho, tener unos huevos de acero" 25 .

Los chicos son irónicamente bautizados con un rito respecto a la tribu: "Aquí uno se hace más hombre, aprende a conocer la vida"26, suponiendo la transformación y autodestrucción humana para adaptarse con el grupo. Vargas Llosa habla explícitamente de la violación del individuo en el marco de su "crecimiento orgánico, natural". El artista afirma que los oficiales violan a los reclutas porque la jerarquía militar es más viva que nunca a través del sangriento "bautismo" según el fragmento siguiente:

El Esclavo no recuerda la cara del muchacho que fue bautizado con él. Debía ser de una de las últimas secciones, porque era pequeño. Estaba con el rostro desfigurado por el miedo y, apenas calló la voz, se vino contra él, ladrando y echando espuma por la boca y de pronto el Esclavo sintió en el hombro un mordisco de perro rabioso y entonces todo su cuerpo reaccionó y mientras

\footnotetext{
${ }^{24}$ La ciudad y los perros..., p. 20.

${ }^{25}$ La ciudad y los perros..., p. 15.

${ }^{26}$ La ciudad y los perros..., p. 13.
} 
ladraba y mordía, tenía la certeza de que su piel se había cubierto de una pelambre dura, que su boca era un hocico puntiagudo y que, sobre su lomo, su cola chasqueaba como un látigo ${ }^{27}$.

La comunidad no se deja aparte. Los estudiantes se confrontan, se pelean y se violan como animales. El diálogo convoca la profunda depresión y la inevitable miseria humana, la desesperación sin salida, el fracaso eterno. Los perros se sienten más perros, se sienten nulos en frente del macrocosmos colectivo y del microcosmos individual y quieren huir, escapar, desaparecer, tal vez morir:

- Basta - dijo la voz -. Ha ganado usted. En cambio, el enano nos engañó. No es un perro sino una perra. ¿Saben qué pasa cuando un perro y una perra se encuentran en la calle?

- No, mi cadete - dijo el Esclavo. - Se lamen. Primero se huelen con cariño y después se lamen.

Y luego lo sacaron de la cuadra y lo llevaron al estadio y no podía recordar si aún era de día o había caído la noche. Allí lo desnudaron y la voz le ordenó nadar de espaldas, sobre la pista de atletismo, en torno a la cancha de fútbol. Después lo volvieron a una cuadra de cuarto y tendió muchas camas y cantó y bailó sobre un ropero, imitó a artistas de cine, lustró varios pares de botines, barrió una loseta con la lengua, fornicó con una almohada, bebió orines, pero todo eso era un vértigo febril y de pronto él aparecía en su sección, echado en su litera, pensando: "Juro que me escaparé. Mañana lo mismo"28.

La protesta del autor se convierte en una estrategia transformadora denunciando a los delincuentes, viciosos, demoníacos que desean salir vivos a pesar de sus pecados o crímenes. La violencia en nivel primario e instintivo está acumulada en el personaje de Boa, mientras el Poeta resulta ser más coherente y articulado entre los miembros del Círculo, pero también un cobarde, un corrupto y pragmático. Según el investigador Jean Franco:

El Jaguar, que es uno de los miembros con mayor individualidad y más auténtico del Círculo, es un individualista frustrado. La diversidad de enfoques sugiere la complejidad de las posturas morales, las relaciones que cambian constantemente de un cadete a otro y los puntos en los que el sistema prevalece sobre los individuos ${ }^{29}$.

Así se concluye la vida existencial en la Academia Militar Leoncio Prado. Refiriéndose al arte de Vargas Llosa y a su cosmovisión artística, el crítico Jesús Armas Marcelo define la novela La ciudad y los perros como una peculiar,

${ }^{27}$ La ciudad y los perros..., p. 21.

${ }^{28}$ La ciudad y los perros..., p. 21.

${ }^{29}$ Jean Franco, "Prosa contemporánea de Mario Vargas Llosa", en Historia de la Literatura hispanoamericana, Barcelona, Ariel, 2010, pp. 339-340.

Araucaria. Revista Iberoamericana de Filosofia, Política, Humanidades y Relaciones Internacionales, año $22, \mathrm{n}^{\circ} 43$. Primer semestre de 2020. Pp. 467-490. ISSN 1575-6823 e-ISSN 2340-2199 https://dx.doi.org/10.12795/araucaria.2020.i43.23 
representación verbal de la realidad y que los límites de la literatura realista son los de la realidad, porque la novela no tiene límites, puesto que a la realidad pertenecen los hechos, los sueños y los mitos humanos. Las pesadillas de Kafka, las laboriosas ficciones psicológicas de Proust o Dostoievski, la impecable objetividad de Hemingway, la mítica de Carpentier, las fantasmagorías alucinantes de un Cortázar, para expresar zonas diferentes, niveles distintos de una sola realidad. En otras palabras, toda la literatura buena es, en última instancia, realista ${ }^{30}$.

\section{El cosmos andino bajo el terror de Sendero Luminoso}

La atmosfera de violencia y el terrorismo ejercido por Sendero Luminoso (1980-2000) se reflejan en modo sugestivo en la novela Lituma en los Andes de Mario Vargas Vargas Llosa, obra novedosa gracias al tratamiento de su trama policiaca. En ella se puede observar al grupo armado en su línea discursiva encabezada por el código terrorista y sus "pragmáticos mecanismos" de ejecuciones diarias, torturas desesperadas, castigos inhumanos y tumbas colectivas. Por esta razón vemos conveniente plantear el perfil terrorista de Sendero Luminoso, aparecido en Lituma en los Andes. Su origen consiste en la oposición histórica de toda América Latina hacia la modernización, el crecimiento económico y la cercanía con los Estados Unidos (como factores que impulsaron la creación de las guerrillas y la lucha armada en el dicho continente). Según Ríos y Azcona:

El crecimiento económico y la cercanía a Estados Unidos no eran razón suficiente para contener y controlar la orientación de los sistemas políticos latinoamericanos. Sistemas profundamente excluyentes, con ingentes niveles de desigualdad social, los cuales se incrementaron notablemente durante los años sesenta y setenta del siglo XX, a lo que se añadía la condición de vulnerabilidad y exclusión social que abrazaba a millones de ciudadanos, proliferaron en la región bajo una suerte de caudillismo, patronear la política y restringir de derechos sociales. Precisamente en este escenario intricado las democracias latinoamericanas en buena medida se colapsan y experimentan una involución en la que confrontan dos maneras de orientar el ejercicio del poder: la dictadura militar desde arriba o planteando desde abajo el sueño de la revolución social ${ }^{31}$.

Sendero Luminoso nace en la Universidad Nacional de San Cristóbal de Huamanga, muy vinculadas a las organizaciones estudiantiles y direcciones universitarias. Según Marté Sánchez Villagómez, es relevante el creciente

\footnotetext{
${ }^{30}$ Juan Jesús Armas Marcelo, Vargas Llosa. El vicio de escribir, Madrid, Alfaguara, 2002, p. 43.

31 Ríos, Jerónimo; Azcona, José Manuel, Historia de guerrillas en América Latina, Madrid, Catarata, 2019, p. 5.
} 
número de los jóvenes estudiantes que se encuadraron en las filas del Partido Comunista Peruano:

SL empezó a reclutar a estudiantes universitarios, una población asentada mayoritariamente en los barrios que iban creciendo o creándose alrededor de la ciudad de Huamanga a consecuencia de la migración rural. Así, jóvenes de extracción campesina se convertirían en la base política de esta organización y sus futuros combatientes. Ello no significó el abandono de las posiciones que lograron con las dirigencias campesinas de federaciones locales y regionales a lo largo de su estadía dentro del Partido Comunista Peruano durante la década de los $1970^{32}$.

Sendero Luminoso inspiraba el cambio político del país aplicando el pensamiento revolucionario a través del líder político de la época Abimael Guzmán, autoproclamado "el más grande marxista-leninista-maoísta vivo sobre la faz de la tierra", según la declaración del I Congreso del PCP-SL en $1988^{33}$. Tomando como referencia a Mariátegui ${ }^{34}$, Sendero se aproxima a las cinco leyes generales que irían a aplicarse en el marco de lucha de clases, justificando directamente la aplicación de la previa lucha armada dentro del contexto de "un necesario cambio revolucionario". Las referencias documentales de la época confirman una sociedad peruana subdesarrollada y dependiente del sistema capitalista. Así, la revolución peruana debería cumplir las condiciones de un verdadero movimiento nacional y democrático respetando la primacía rural del país. Esta filosofía se refleja fielmente en los discursos de Guzmán caracterizados por su impronta marxista-leninistas-maoísta:

\begin{abstract}
Revolución de Nueva Democracia// En revolución antiimperialista y anti feudal que solo el proletariado, mediante su partido, es capaz de conducir siguiendo el camino de cercar las ciudades desde el campo y liberando una prolongada guerra popular. // Este es el camino que el presidente chino Mao estableció para los países como el nuestro y el camino que nuestro fundador nos señalaráa ${ }^{35}$.
\end{abstract}

${ }^{32}$ Marte Sánchez, "Sendero Luminoso", en Jerónimo Ríos y José Manuel Azcona, Historia de guerrillas en América Latina, Madrid, Catarata, 2019, p. 143.

33 También la perspectiva ideológica y política de la agrupación senderista fue proclamada como la única línea justa y correcta del partido, su única voz autorizada revocando la voz del líder comunista chino Mao Zedong quien subrayaba "el que sea correcta o no la línea ideológica y política lo decide todo. Cuando la línea del partido es correcta, lo tenemos todo. Si no tenemos hombres, los tendremos; si no tenemos fusiles, los consiguiéremos; si no tenemos el poder, lo conquistaremos; Si la línea es incorrecta, perderemos lo que hemos obtenido. La línea política es como la cuerda clave de una red, si tiramos de ella todas las mallas se abrirán. Hay que practicar el marxismo y no el revisionismo; unirse y no escindirse; ser francos y honrados y no urdir intrigas ni maquinaciones". Villagómez en "Sendero Luminoso...", p. 145.

34 José Carlos Mariátegui fue fundador del Partido Socialista de Perú en el año 1928.

35 "Sendero Luminoso...," p. 147. 
La implementación de la Ley de la Reforma Agraria en Perú, aplicada el 24 de junio de 1969, puso en práctica la descentralización de las tierras agrícolas (antes bajo el patrimonio de los latifundistas) liberando a los campesinos de la servidumbre histórica ${ }^{36}$. Aun con todo, el establecimiento de la lucha armada sentaría sus bases, entre otros momentos, en 1978 cuando Guzmán aprueba el esquema de cercar las ciudades y abrir el camino a las acciones militares en el campo bajo el lema " ¿Desarrollar la guerra popular sirviendo a la revolución mundial!"37. Los materiales archivísticos más actualizados confirman el perfil sanguinolento de Sendero Luminoso cometido y vivido en los límites rurales de Ayacucho. Mencionamos el año trágico del 1984 que produjo más de $19 \%$ del número total de víctimas, muertos y desaparecidos. La historia sangrienta escrita por la organización terrorista Sendero Luminoso terminará con la captura de su líder Abimael Guzmán el 12 de septiembre de 1992 junto con otros colaboradores, como Elena Iparraguirre, Laura Zambrano y María Pantoja, conocidos miembros del Comité Central de la organización ${ }^{38}$.

Dicha realidad sangrienta se refleja artísticamente en la novela Lituma en los Andes justificando fielmente la crueldad obtusa y el fracaso de los ideales derrocados por el sectarismo marxista-leninista-maoísta. Por primera vez el escritor peruano mezcla elementos de la narración policiaca con los tonos puramente sentimentales. El cosmos andino se llama "Andamarca", organizada en forma de un campamento minero de las montañas. La narración inicia con la visita del cabo Lituma y su adjunto Tomás quienes viven temporalmente en un ambiente bárbaro y hostil, bajo la constante amenaza de los guerrilleros senderistas, y debatiéndose con misterios sin aclarar que les obsesionan, como ciertas desapariciones inexplicables. Allí se encuentra la complicidad vital, la trágica pobreza e ilimitado olvido político. Predomina el silencio de las cimas combinado irónicamente con el silencio humano. La impresión primaria ofrece un escenario kafkiano donde lo crímenes cometidos son refrenes cotidianos

\footnotetext{
36 "Los senderistas apoyaban la lucha anti feudal y la confrontación antiimperialista para poder conseguir verdaderamente la democracia deseada. Los instrumentos revolucionarios según las referencias históricas y propagandísticas de la época eran constituidos por una unidad triangular: partido, ejército y frente único. La base ideológica resulta de ser una aplicación de la obra maoísta Sobre la dictadura democrática popular en la que se sustenta irónicamente: Un partido disciplinado, pertrechado con la teoría marxista-leninista y que practica la autocrítica y se mantiene ligado a las masas populares; un ejército dirigido por tal partido; un frente único de todas las clases y grupos revolucionarios dirigidos por tal partido; estas son las tres armas principales que hemos derrotado al enemigo". "Sendero Luminoso...", p. 148.

${ }^{37}$ Marté Sánchez pone de relieve informaciones archivadas del Sendero Luminoso por donde se marca la distribución porcentual de la guerra armada según el mapa de las zonas controladas como "la región de Ayacucho y su área de influencia por donde se desarrollaron el grueso de sus acciones, (guerra de guerrillas, propaganda y agitación armada, sabotaje y aniquilamiento selectivo), con un total de 63,4\%, seguido por 'otras regiones' con el $28,2 \%$, y Lima metropolitana con 8,4 \% por cierto", "Sendero Luminoso", p. 152.

38 Marté Sánchez y Jerónimo Ríos, Breve historia de Sendero Luminoso, Barcelona, Revuelta, 2018, p. 117.
} 
sin justificar la trágica noticia de un hombre desaparecido y la denuncia de su mujer en quechua:

\begin{abstract}
Era una mujer la que había denunciado la desaparición del albino: El hombre había salido a trabajar, y no había llegado a su destino. Pedrito bajó al pueblo a comprar una botella de cerveza para los guardias y nunca regresó. Nadie los había visto, nadie había notado en ellos miedo, aprensión, enfermedad, antes de que se esfumaran... Después de tres semanas, el cabo Lituma y el guardia Tomás Carreño seguían tan en la luna como el primer día ${ }^{39}$.
\end{abstract}

La animación vital parece extremamente reducida gracias a las condiciones físicas del terreno montañoso. Las únicas oportunidades naturales se relacionan con la escasa ganadería o minería, mientras el analfabetismo no constituye una emergencia educativa. El cosmos tiene sus instituciones y detalles, muchos prejuicios y creencias que atacan y castigan a los vivos.

Los discursos fantasmagóricos de los habitantes se realizan entre la línea real-irreal por su propia facilidad de comunicar con los demonios, las sombras, brujas, diablos, quienes deciden paradójicamente por el destino de los conscientes. La subconsciencia de los andinos convive con la retrospectiva de los llamados "pishtacos", con transcendencia canibaliza. Los habitantes serranos según la percepción del escritor son duros y, nada sentimentales, impregnados y unificados con la cordillera.

El escritor mezcla la mitología local de carácter universal con el misterio del presente sintetizado en la organización terrorista de Sendero Luminoso. El tiempo tiene referencias a los años negros escritos en la historia de Perú. La intriga posmoderna de Vargas Llosa incluye simultáneamente lo físico y lo metafísico, el vivo y el muerto, la esperanza con la pérdida, la vida con la fatalidad. El misterio prevalece sin control en el seno más profundo de los Incas. Estos personajes epigámicos enfrentan el peligro terrorista, el ataque estatal y la guerra histórica de Naccos. Andamarca representa el "macrocosmos" andino por su extensión inmensa y sus desapariciones misteriosas de gente.

Lituma, como protagonista de novela, describe el sentimiento del terror y nada acogedor que siente en el seno de la cordillera entre truenos y terremotos. Pero era

De otra tormenta que se le venía por encima, por la espalda. Hasta los elementos naturales eran traidores en estos Andes de porquería. ¿Qué chucha pasaba? ¿Temblor? ¿Terremoto? Ahora no le cabía duda: el suelo temblaba bajo sus pies y olía a aguarrás. Lo rodeaba un ruido ronco, profundo, que salía del corazón de la montaña. Alrededor, entre sus pies, empujadas o espantadas

${ }^{39}$ Mario Vargas Llosa, Lituma en los Andes, Barcelona, Planeta, 2017, p. 16. 
por manos invisibles, rodaban piedrecillas, lascas, y se dio cuenta de que, inconscientemente, buscando protegerse, se había colocado a cuatro patas bajo una alta roca puntiaguda, con manchas de musgo verdoso amarillentas. ¿Qué pasa, Dios mío, que está pasando? -gritó, persignándose y esta vez no hubo eco alguno porque ese ruido denso, múltiple, omnipresente, ese ronquido granítico, ese rodar montaña abajo se tragaba todos los ruidos. Decían que la madre de Dionisio la había matado un rayo. ¿Lo mataría otro a él? Temblaba de pies a cabeza y el miedo le había llenado las manos de sudor. No quiero morirme, Diosito, por lo más santo -gritó, sintiendo su garganta rajada y reseca ${ }^{40}$.

Las líneas diacrónicas narrativas están triplicadas estructuralmente porque se habla de tres crímenes ocurridos a la vez y tres víctimas: Pedro Tinoco, Casimiro Huarcaya y Don Medardo Llantac. El posmoderno habla del anónimo: "Nadie", "ningún", "ninguna" aparecen por doquier, mientras la milicia de Sendero Luminoso sigue derramando más sangre y cadáveres. Andamarca genera angustia existencial, misterio, miedo apocalíptico, temblor, muerte. Vargas Llosa describe artísticamente Sendero Luminoso, acentuando la edad y el armamento, como marcadores de seres sangrientos, salvajes:

En sus filas predominaban los jóvenes y los hombres, pero había también mujeres y niños, algunos de los cuales no debían llegar a los doce años. Los que no iban con metralletas, fusiles o revólveres, llevaban viejas escopetas de caza, garrotes, machetes, cuchillos, hondas y, en bandolera, como los mineros, cartuchos de dinamita. Llevaban también banderas rojas con la hoz y el martillo, que izaron en el campanario de la iglesia, en la asta de la casa comunal y en la copa de un pisonea de flores rojas que dominaba el pueblo ${ }^{41}$.

La milicia captura a los débiles como al alcalde, al juez de paz, al jefe de correos, a los dueños de tres bodegas y a sus mujeres, a dos desmovilizados del ejército, al boticario y prestamista Don Sebastián Yupanqui y a los dos técnicos enviados por el Banco Agrario. Y luego "los llevaron hasta la plaza de la iglesia, donde el resto de la milicia había congregado al pueblo. Sus caras eran descubiertas" ${ }^{\text {. }}$. Captura a "los mallos" de Andamarca, con indiferencia de condición social:

Vino el juicio de los malos...detritus putrefacto que el régimen capitalista feudal, sostenido por el imperialismo norteamericano y el revisionismo soviético, fomentaba para adormecer el espíritu combativo de las masas. También eso se combatiría. En el incendio purificador de la pradera que era la Revolución ardería el individualismo egoísta burgués y surgirían el espíritu colectivista y la solidaridad de clase ${ }^{43}$.

${ }^{40}$ Lituma en los Andes..., p. 82.

${ }^{41}$ Lituma en los Andes..., p. 80.

${ }^{42}$ Lituma en los Andes..., p. 80.

${ }^{43}$ Lituma en los Andes..., p. 83. 
Los castiga para "poner la justicia popular":

Unas veintenas de hombres y mujeres fueron juzgados, sentenciados, azotados, multados, obligados a devolver lo que habían adquirido. ¿Cuántas acusaciones eran ciertas, cuántos inventos dictados por la envidia y el rencor, producto de la efervescencia en la que todos se sentían empujados a competir, revelando las crueldades e injusticias de que habían sido víctimas? ${ }^{44}$

Siguiendo al texto, Sendero Luminoso ejecuta en nombre de la ideología maoísta y deja a sus cadáveres insepultos:

Cuando don Medardo y el alférez preguntaron por qué no habían enterrado a los muertos, no supieron que responder. Nadie se había atrevido a tomar la iniciativa, ni siquiera los parientes de las víctimas, paralizados por un supersticioso temor a atraer de nuevo a la milicia o desatar otra catástrofe si tocaban, aunque fuera para enterrarlos, a esos vecinos a los que se acababan de chancar cabezas, caras y huesos, como si se tratara de enemigos mortales...

La muerte en la novela no conoce límites. Los muertos son muchos y diarios:

Luego llevaron a los muertos al cementerio, cavaron tumbas y los enterraron. Solo entonces reaccionaron los parientes con el dolor y la cólera que era de esperar. Lloraban las viudas, los hijos, los hermanos, los sobrinos y los enteados; se abrazaban, y, maldiciendo, los puños al cielo pedían venganza ${ }^{45}$.

El código connotativo terrorista está caracterizado por una doble violencia que al final se unifica en una. El nudo gordiano consiste en la siguiente constatación: el código violento de los serranos siempre encuentra la luz al final del túnel, y se justifica por la historia y la antropología de los Incas. Mientras el código violento de Sendero Luminoso no hay explicación, sino sumisión, adhesión, porque está justificado políticamente y es la perspectiva revolucionaria, como se manifiesta en las consignas de las paredes de las casas: “¡Viva la Lucha Armada!”, „Viva la guerra popular!”, “¡Viva el marxismoleninismo!", “¡Muerte al imperialismo y al revisionismo!”, “iMuerte a los traidores!”, “Muerte al régimen genocida y anti obrero!”. Se recluta hasta a los menores que eran capaces de contemplar a las vicuñas muertas sin temor, porque vivían con la muerte y podrían generar muerte, justificándola con cinismo:

${ }_{44}^{44}$ Lituma en los Andes..., p. 84.

45 Lituma en los Andes..., p. 87.

Araucaria. Revista Iberoamericana de Filosofia, Politica, Humanidades y Relaciones Internacionales, año $22, \mathrm{n}^{\circ} 43$. Primer semestre de 2020. Pp. 467-490. ISSN 1575-6823 e-ISSN 2340-2199 https://dx.doi.org/10.12795/araucaria.2020.i43.23 
Ésta es una guerra, nadie puede decir no va conmigo. Va con todo el mundo, incluidos los mudos y los sordos y los opas. Una guerra para acabar con los «señores». Para que nadie se arrodille ni le bese las manos ni los pies a nadie ${ }^{46}$.

No quedan atrás los jóvenes campesinos, escribe Vargas Llosa, gracias a la camarada Teresa y al camarada Juan:

\begin{abstract}
Debían asimilarlos, actuar como ellos si hubieran nacido aquí y tuvieran sus muertos, entre los del pueblo. Luego, cocinaron, comieron y se repartieron por las casas y durmieron junto a los vecinos, muchos de los cuales velaron esa noche, turbados, incrédulos, inseguros, asustados, con lo que habían hecho, visto y oído...Al amanecer entre los más jóvenes escogieron a unos cuantos muchachos y muchachas para la milicia. Cantaron sus himnos, $\mathrm{y}$, dando sus gritos de victoria, hicieron flamear las banderas rojas ${ }^{47}$.
\end{abstract}

Porque nadie podría mover o actuar como los andamarquinos para ejecutar y matar a las hienas del gobierno, para tirotear a los obreros y para defenderse del imperialismo y revisionismo, matando a los burgueses y a los ricos. La revelación de hechos, testigos, datos, momentos, afirmaciones, detalles, empujan la verdad trágica. La novela de Vargas Llosa Lituma en los Andes denuncia la violencia totalitarista, la corrupción estatal y la falsedad humana en vísperas de la autodestrucción, un asunto recurrente hasta en la época actual.

\title{
5. Conclusiones
}

Mario Vargas Llosa es actualmente uno de los artistas indiscutibles de la literatura cosmopolita universal, con obras abrumadoras y auténticas, impregnadas por el existencialismo vital y la lírica sentimental, las luces y las sombras del verdadero artista. Nunca le faltó la lucidez, la locura necesaria para asumir su vocación del escritor diario, incondicional y de furiosa inmolación. El estudio confirma el temprano compromiso político de Vargas Llosa al lado de su recorrido literario, justificándolo como inclinación e incorporación intelectual muy de moda en los años 60, gracias a la simpatía por el existencialismo cultural de Sartre y Marcuse, (representantes ideológicos de la izquierda francesa) y por la Revolución cubana. El escritor peruano, con la influencia de Machado, Unamuno, Valle-Inclán, Baroja, proclama la discusión estético-ideológica como "realismo social" y "reflexión colectiva". El escrito plantea firmemente la tesis del cambio revolucionario en el campo literario como "prueba de amor"48, creando una cultura política transformadora.

\footnotetext{
${ }^{46}$ Lituma en los Andes..., p. 57.

${ }^{47}$ Lituma en los Andes..., p. 86.

${ }^{48}$ La literatura es fuego..., idem.
} 
Su narrativa, mantiene una apariencia despreocupada hacia las formas exteriores de la creación literaria, porque la verdadera batalla del libro se libra donde dos actitudes ante la realidad y el hombre se descubren antagónicas. El novelista implementa la teoría del túnel, señalándola como "destrucción lingüística sugestiva", "agresión receptiva", "abandono y despedida tradicional". También muestra originalidad por utilizar la técnica contrapuntística y combinar escenas alternativas, reflejando los conflictos de cada época y las tensiones injustificadas que transcurren a la raza humana. Su pluma reconstruye la peripecia vital del personaje, quien recurre al conocido flashback, saltando de un plano temporal al otro. La narrativa de Vargas Llosa rebosa apuntes biográficos convertidos literariamente en reflexiones psicológicas. En lo que respecta a su narrativa, aparentemente los tonos estéticos respectivos se convierten insólitos y rebeldes por el recorrido oscuro de su túnel referencial, impactante, escandaloso, temeroso, extraordinario que supera la misma ficción, hiperbólico y casi perverso. Vargas Llosa transforma el texto literario en una forma de manifestación verbal que sirve a la exanimación del método, del mecanismo del terror y de la violencia.

Mario Vargas Llosa enfrenta artísticamente en la novela La Ciudad y los perros el pasado simbólico con el presente psicológico, ironizando y denunciando duramente la violencia en la academia militar. Los impresionantes escenarios desvelan con estilo amargo el racismo humano, el machismo injustificado y la injusticia desflemada y bien presente en la sociedad peruana de la época. El mérito de autoría consiste en la aportación de una visión extensa y temerosa de la violencia física, psicológica, genérica o sociocultural. La narrativa de Vargas Llosa manifiesta la dualidad imaginativa paragógica, constituida por la imagen extrínseca (la educación militar dentro del contexto urbano) y la imagen intrínseca (la imagen urbana dentro del contexto educativo de los años 50). Paralelamente la novela Lituma en los Andes es una impactante imagen de la atmosfera guerrillera y del terrorismo ejercido por Sendero Luminoso. Gracias a la trama policíaca, el texto ofrece una revisión del grupo armado y sus "pragmáticos" mecanismos. Dicha realidad sangrienta se refleja en Lituma justificando la crueldad obtusa y el fracaso de los ideales.

\section{Referencias bibliográficas:}

Armas, J.J. (2002). Vargas Llosa. El vicio de escribir. Madrid: Alfaguara.

Bellini, G. (1997). "La narrativa del siglo XX: La nueva novela y su auge. Mario Vargas Llosa”. En Giuseppe Bellini, Nueva historia de la literatura hispanoamericana. Madrid: Castalia. 
Bono, F. (2015). "La literatura tiene efectos en la vida, pero no se pueden premeditar", en El País, 17 de septiembre 2015 www.elpais.com/ cultura/2015/09/17/actualidad/1442500868_851297.html

Cortázar, J. (2006). "El intelectual y la política en Hispanoamérica”, en Julio Cortázar, Obra Critica, Obras Completas VI. Barcelona: Galaxia Gutenberg.

Franco, J. (2010). "Prosa contemporánea de Mario Vargas Llosa", en Jean Franco, Historia de la Literatura hispanoamericana. Barcelona: Ariel.

Gnutzmann, R. (2008). "Eclosión y diversificación: Novela y cuento desde los años sesenta en Perú", en Rita Gnutzmann, Historia de la Literatura Hispanoamericana. Tomo III, Siglo XX. Madrid: Cátedra, 2008.

López, H. (2011). Historia del Perú: La República Contemporánea (19332010). Lima: El Comercio.

Mainer, J. C. (2014). "Síntomas del malestar”, en José Carlos Mainer, Historia mínima de la literatura española. Del "Cantar de Mio Cid al siglo XXI. Madrid: Turner Publicaciones.

Martínez, M.E. (s.f.). "La literatura es fuego", en Literaterra, el portal de la literatura en español, www.literaterra.com/mario_vargas_llosa/la_ literatura_es_fuego/

Ortiz, E. (2017). “¿El realismo mágico hispanoamericano constituye un movimiento estético?", en Enrique Ortiz, La literatura hispanoamericana en 100 preguntas. Madrid: Ediciones Nowtilus.

Oviedo, J. M. (2012). "Vargas Llosa: Jerarquías de la realidad y el poder", en José Miguel Oviedo, Historia de la Literatura Hispanoamericana. De Borges al Presente. Madrid: Alianza.

Ríos, J. y Azcona, J.M. (2019). Historia de las guerrillas en América Latina. Madrid: Catarata.

Sánchez, M. y Ríos, J. (2018). Breve historia de Sendero Luminoso. Lima: Revuelta Editores.

Varga Llosa, M. (1997). La ciudad y los perros, Madrid: Alfaguara.

Vargas Llosa, M. (2017). Lituma en los Andes, Barcelona: Planeta.

Vargas Llosa, M. (2017). "El escritor y sus demonios", en Chicago Tribune, 25 de abril de 2017, www.chicagotribune.com/.../ct-hoy-8834484-mariovargas-1

Sánchez, M. (2019). "Sendero Luminoso", en Jerónimo Ríos y José Manuel Azcona (Eds.) Historia de las guerrillas en América Latina. Madrid: Catarata, Madrid. 